\title{
EL DERECHO DE FAMILIA ANTE LA AGENDA 2030 DE LAS NACIONES UNIDAS
}

\author{
FAMILY LAW IN THE UNITED NATIONS 2030 AGENDA
}

Carmen Meza Ingar ${ }^{1}$

\section{Resumen}

El fenómeno de la globalización cultural ha llevado también el concepto de los derechos humanos a todos los rincones de la tierra. En tal virtud, los avances sobre el desarrollo de los pueblos gracias a la tecnología, podría hacer posible una promoción humana que lleve prosperidad a muchas regiones y por tanto, a todas las familias, incluso, las más pobres de la humanidad. Es preocupación de los expertos y de los políticos que han planeado esfuerzos continentales y mundiales para hacer realidad que se superen problemas de larga data, como la pobreza, las enfermedades y el analfabetismo.

Si bien el 2015, fecha señalada por los Objetivos del Milenio, no tuvo los logros prometidos, sirvió para que se elaborara la AGENDA 2030, que renueva los compromisos de los Estados para hacer posible un mundo nuevo para las nuevas generaciones.

Confiamos en que los nuevos planteamientos, acompañados de presupuestos realistas, hagan posible las metas señaladas.

Palabras clave: Derecho, sociedad, desarrollo sostenible.

\section{Abstract}

The phenomenon of cultural globalization has also brought the concept of human rights to all corners of the earth. Thus, the development achieved by peoples thanks to technology could make possible human promotion bringing prosperity to many regions and, therefore, to all families, including the poorest. This is a concern of experts and politicians who have planned continental and world-wide efforts to overcome long-standing problems such as poverty, disease, and illiteracy.

Abogada, investigadora y docente universitaria. Doctora en Derecho por la Universidad Nacional Mayor de San Marcos. Presidenta fundadora de la Academia Peruana de Doctores en Derecho. Actualmente, se desempeña como docente en la Facultad de Derecho de la UNMSM dictando los cursos de Derecho de Familia, Derechos Humanos y Derecho Constitucional. Autora de diversos artículos y libros de su especialidad. Correo electrónico: cmeza@ unmsm.edu.pe 
Although 2015, a date marked by the Millennium Goals, failed to achieve the proposed goals, it served to prepare the 2030 AGENDA, whereby States have renewed their commitments to make possible a new world for coming generations.

We are confident that the new approaches, accompanied by realistic budgets, will make such goals possible.

Keywords: Law, society, sustainable development.

\section{INTRODUCCIÓN}

La institución familiar, centro y mirada de los científicos, encuestadores y cineastas nos obliga estudiar a la "familia", célula básica de la sociedad y verdadero punto de partida del desarrollo de los pueblos.

La familia es la que da los estudiantes, los profesionales, los ciudadanos y los gobernantes que forman la población, es decir, los Estados que ejercen soberanía en sus territorios, aun cuando los proyectos de integración regional y de desarrollo sostenible modernos, influyen tanto, que podría reflexionarse sobre el viejo y el nuevo concepto de la "libre determinación de los pueblos".

De todos modos, la familia vive en el hogar, dulce hogar, a cargo de los padres. Sin embargo el nuevo derecho reconoce la intromisión del Estado en muchos aspectos. Recordemos palabras de 1891, pronunciadas por el Papa León XIII: “ ....Si alguna familia se hallase en extrema necesidad y no pudiese valerse ni salir de ella por sí en manera alguna, justo sería que la autoridad pública remediase esta necesidad extrema, por ser cada una de las familias una parte de la sociedad. Y del mismo modo, si dentro del hogar doméstico, surgiese alguna perturbación grave de los deberes mutuos, interpóngase la autoridad pública para dar a cada uno lo suyo; pues no es esto usurpar los derechos de los ciudadanos, sino protegerlos y asegurarlos con una justa y debida tutela" ${ }^{2}$.

Por eso, es necesario reconocer que la familia inicialmente fue regulada por el Derecho Privado; sin embargo, cada día es más fuerte la corriente social y la que aboga por la influencia del Derecho Público en la legislación del Derecho de Familia.

Su Santidad León XIII: “Encíclica Rerum Novarum”. 


\section{HISTORIA DE LA FAMILIA}

La familia es una institución tan antigua que aparece en los Códigos de Hammurabi y de Manu, en la cultura universal. En las páginas de la Biblia aparece también la familia formada por los padres Adán y Eva con sus hijos Caín y Abel, incluso tenemos noticia de uno de los crímenes más comentados, dada la crueldad del protagonista.

El antiguo Perú tiene también la historia de la familia peruana pre hispánica y algunas de sus formas, como el servinacuy ha sobrevivido, pese a la importancia de la vida colonial que tuvo influencia social y jurídica en el Virreynato del Perú.

La familia, basada en el matrimonio se encuentra en todas las culturas y civilizaciones, como garantía de la perpetuidad de la especie.

Las Partidas, decían sobre el matrimonio, que era "la sociedad legítima del hombre y de la mujer, que se unen con vínculo indisoluble, para perpetuar la especie, ayudarse a llevar el peso de la vida y participar de una misma suerte." ${ }^{3}$

Modestino definió el matrimonio romano, basado en la comunidad de condición social y de creencias religiosas, como conjunctio maris et feminae, consortium omnis vitae, divine atque humani iuris comunicatio (unión de marido y mujer, consorcio para toda la vida, comunicación del Derecho Humano y del divino).

Entre los musulmanes el matrimonio no es monogámico. Cuando se revisó las legislaciones de diversos sistemas jurídicos, llegando al nuevo milenio de la cristiandad, se verificó que casi todos los Estados disponen que el matrimonio es la unión de un hombre y una mujer. Este concepto del matrimonio monogámico, en la fecha en la que se aprobó la Carta de los Derechos Humanos, 1948, originó que ocho Estados, miembros de la ONU, se abstuvieran de votar, por tener diferente legislación y por no estar autorizados a aprobar que existe el principio de igualdad entre hombres y mujeres. La conciencia del mundo se expresa a favor de la monogamia, aun cuando las prácticas de las poblaciones rurales o de antiguos matrimonios establecidos continúen practicando la poligamia, en Malí, por ejemplo.

Partidas, Legislación Española (1958) Fondo Editorial de la Pontificia Universidad Católica del Perú. 
Las nuevas generaciones, los jóvenes que estudian en Europa, ven otros modelos de familia.

En esta tendencia ha ayudado la difusión de la Convención para eliminar todas las formas de discriminación contra la mujer, que afirma que hombres y mujeres tienen el mismo derecho para contraer matrimonio, art. 16, literal a) y el literal b) el mismo derecho para elegir libremente cónyuge y contraer matrimonio, solo por su libre albedrío y pleno consentimiento.

También debe tenerse presente el conflicto de intereses que puede generarse, a veces, entre los hijos y la madre. El mismo art. 16 pre citado en su literal g) da la solución ante esos casos, preceptuando que "el interés de los hijos es primordial".

En la historia de la familia se encuentran instituciones clásicas como la "patria potestad" y también el decaimiento del vínculo matrimonial, que genera crisis en los hijos menores. La legislación de Brasil en su Código de 2002 dice: "potestad familiar", reconociendo que no solo el padre ejerce el cargo, sino la madre. En el Código Civil Peruano de 1984 se incluye a ambos padres: padre y madre, pero con las palabras latinas referidas al padre. El Código de 1984, que tuvo muchas correcciones dada su sistemática y falta de exposición de motivos, su art. 423 numeral 3 referido a que "los padres corregirán moderadamente...", fue derogado por Ley 30403 de fecha 30 de Diciembre de 2015, porque no había claridad en la norma y muchos padres castigaban severamente a sus pequeños hijos. Dicha derogatoria alcanzó también al art. 74 literal d) del Código de los Niños y Adolescentes. Es que ambos cuerpos de leyes proponían a los padres de hijos desobedientes que solicitaran internamiento de sus pequeños en los institutos de menores, situación imposible, porque los albergues e institutos están sobre poblados y no cuentan con recursos para atender debidamente a los tutelados.

La Patria potestad, como decimos data del Derecho Romano, fue estudiada en el año 542 después de Cristo, por Justiniano, en forma integral, dentro de la familia y cuando había separación o divorcio. Como él era contrario al divorcio, lo penalizó en el communi consensu del capítulo I de la Novela 117. ${ }^{4}$

Se trata de un capítulo amplio, pero interesa el capítulo 7mo referido a la guarda y custodia de los hijos y el derecho a ser alimentados por sus progenitores divorciados, en los procesos de divorcios contenciosos culpables. Lo importante de este capítulo 1 de la Novela 117 es que afirma que en casos

Los textos originales de Justiniano están en griego. 
de disolución de matrimonio, los hijos no debían sufrir ningún perjuicio - nati filii nullo modo laedantur ex separatione nuptiarum-, siendo en esa época llamados a herencia y alimentados con el patrimonio del padre -sed ad parentum hereditatem vocentur ex patris substancia indubitander alendi.

En la época de Justiniano para resolver la custodia y guarda de los hijos se utilizaba el criterio de la culpabilidad en la disolución nupcial, sin distinción de sexo. El progenitor culpable no tenía la custodia de los hijos, sino el otro progenitor. Y había casos de falta de disponibilidad económica del padre. La Ley decía que en esos casos, los hijos pobres podían quedar bajo la custodia de la madre.

El Derecho Romano influyó en los autores del Código Francés de 1804, el que inspiró a los codificadores del siglo XIX.

\section{TRATADOS INTERNACIONALES}

El siglo XX fue muy rico en Tratados Internacionales que proporcionan instrumentos jurídicos a favor de las personas y de las familias, sin embargo fue el más cruento de la historia, si consideramos las consecuencias mundiales de las dos guerras que se iniciaron en Europa.

No obstante ello, se debe reconocer el valor e importancia de la Carta Universal de Derechos Humanos, adoptada el 10 de diciembre de 1948, así como dos Convenios muy importantes, el referido a la Convención para eliminar todas las formas de discriminación contra la Mujer, que data del 17 de diciembre de 1979 y la Convención de los Derechos del Niño, adoptada el 20 de noviembre de 1989, y que constituye los Derechos Humanos de los niños del mundo entero.

La Carta Universal de Derechos Humanos proclama la igualdad de hombres y mujeres, declarando que todos por ser seres humanos nacemos con igual dignidad y derechos. Todos merecemos ser tratados como seres superiores de la humanidad por ser inteligentes, tener voluntad y actuar en la sociedad.

El desarrollo de los Derechos Humanos dio lugar a una serie de Convenciones o Tratados Internacionales, como la expedida para prevenir y sancionar el genocidio, la que prohíbe el tráfico de personas y la explotación de la prostitución ajena, sobre el status de los refugiados, sobre igual remuneración por igual trabajo, sobre derechos políticos de la mujer, sobre 
reglas mínimas para el tratamiento de prisioneros, sobre la abolición de la esclavitud, sobre la nacionalidad de la mujer casada, la Convención para la abolición del trabajo forzado, sobre la discriminación en el trabajo, sobre edad mínima, consentimiento y registro de los matrimonios, para eliminar todas las formas de discriminación racial, sobre derechos económicos, sociales y culturales, sobre derechos civiles y políticos, sobre la supresión y sanción del apartheid, sobre erradicación del hambre y la malnutrición.

El estudio del Derecho de Familia se enriquece con varios de los Tratados Internacionales, especialmente con los referidos a la Mujer y a los Niños.

La Convención sobre la eliminación de todas las formas de discriminación de la Mujer se puso en efecto el 3 de setiembre de 1981, cuando fue ratificada por 20 Estados. El Perú demoró la ratificación de este Tratado Internacional hasta el 2 de junio de 1982, por Resolución Legislativa 23432.

El Consejo Económico y Social de las Naciones Unidas sancionó el 20 de noviembre de 1989 la Convención sobre los Derechos del Niño, que fue ratificada por el Perú en 1990 por Resolución Legislativa 25278.

Es tan importante este Tratado Internacional porque ha influido en el mundo entero sobre la regulación de los derechos de los menores de edad, en forma integral.

En efecto, la Convención desarrolla normas referidas a los niños bajo la patria potestad, es decir, que viven en sus propios hogares, a los niños que son declarados en estado de abandono, por no tener padres, o por haber sido totalmente abandonados, a los niños institucionalizados o que viven en albergues o institutos, o en llamados CAR (Centros de Atención y Residencia), tanto de origen público o privado, y a los niños que se encuentren en los conflictos armados.

La Convención recoge diversos sistemas jurídicos del mundo y en cuanto a los niños abandonados da la solución de los albergues o también la adopción, pero para los países islámicos, en el art. 20 reconoce el valor de la "kafala" ya que ellos no admiten la adopción. El derecho islámico regula la sucesión únicamente por ius sanguinis, mas no por adopción. 
Cuando el Perú ratificó la Convención interrogué a varios congresistas que aprobaron la ratificación del Tratado "¿qué es kafala?" No supieron contestarme. ${ }^{5}$

\section{LA CARTA DE LOS DERECHOS DE LA FAMILIA}

La Carta de los Derechos de la Familia responde a un acuerdo del Sínodo de Obispos que estudió en Roma la "Misión de la Familia en el Mundo contemporáneo" en 1980".

Enuncia los derechos que están impresos en la conciencia del ser humano y en los valores comunes de toda la humanidad y declara que la familia es una sociedad natural que existe antes que el Estado o cualquier otra comunidad, y posee derechos propios, que son inalienables.

En su Preámbulo declara que la familia constituye, más que una unidad jurídica, social y económica, una comunidad de amor y de solidaridad, insustituible para la enseñanza y transmisión de los valores culturales, éticos, sociales, espirituales y religiosos, esenciales para el desarrollo y bienestar de sus propios miembros y de la sociedad.

La familia es el lugar donde se encuentran diferentes generaciones y donde se ayudan mutuamente a crecer en sabiduría humana y a armonizar los derechos individuales con las demás exigencias de la vida social.

La familia y la sociedad, vinculadas mutuamente por lazos vitales y orgánicos, tienen una función complementaria en la defensa y promoción del bien de la humanidad y de cada persona.

Muchas familias se ven obligadas a vivir en situaciones de pobreza que les impide cumplir su propia misión con dignidad.

Por ello, la Carta insta a los Estados, Organizaciones Internacionales $\mathrm{y}$ a todas las instituciones y personas interesadas, para que promuevan el respeto de estos derechos $\mathrm{y}$ aseguren su efectivo reconocimiento y observancia.

Declara, asimismo, que todas las personas tienen el derecho de elegir libremente su estado de vida y por lo tanto, derecho a contraer matrimonio y establecer una familia o a permanecer célibes.

La Kafala es un documento notarial del Derecho Islámico, por el que consta el compromiso de sostener económicamente en la familia a niños huérfanos, hijos de parientes o de amigos. 
Aclara, debidamente, que el matrimonio no puede ser contraído sin el libre y pleno consentimiento de los esposos, debidamente expresado.

Los esposos, dentro de la complementariedad que existe, entre hombre y mujer, gozan de la misma dignidad y de iguales derechos respecto al matrimonio.

El art. 4 dice que la vida humana debe ser respetada y protegida absolutamente desde el momento de la concepción. ${ }^{6}$

Precisa en el literal e) que todos los niños, nacidos dentro o fuera del matrimonio gozan del mismo derecho a la protección social para su desarrollo personal e integral.

El art. 5 de la Carta preceptúa que "por el hecho de haber dado la vida a sus hijos, los padres tienen el derecho originario, primario e inalienable de educarlos; por esta razón, ellos deben ser reconocidos como los primeros y principales educadores de sus hijos".

La familia tiene el derecho de esperar que los medios de comunicación social sean instrumentos positivos para la construcción de la sociedad y que fortalezcan los valores fundamentales de la familia. Al mismo tiempo, la familia tiene derecho a ser protegida adecuadamente, en particular, respecto a sus miembros más jóvenes, contra los efectos negativos y los abusos de los medios de comunicación.

\section{EL PERÚ PLURIÉTNICO Y PLURICULTURAL}

La Constitución Peruana de 1993, en el art. 2 , numeral 19 proclama que toda persona tiene derecho a su identidad étnica y cultural. También reconoce y protege la pluralidad étnica y cultural de la Nación.

Más aún, dicho precepto aclara que todo peruano tiene derecho a usar su propio idioma ante cualquier autoridad mediante un intérprete. Los extranjeros tienen este mismo derecho cuando son citados por cualquier autoridad.

De conformidad con la historia del Derecho Peruano, basado en la fuentes escritas por los cronistas que describieron las instituciones pre hispánicas, se sabe que el Estado Inca dio importancia a la institución familiar y el ciclo vital estuvo planificado. Aún dentro del ayllu el Estado Inca destacó a la familia y sobre ellas se fundaron las aldeas, se distribuyó las tierras por tupus dados a los purics, jefes de familia, y tenían tributación.

Es importante reconocer que el Art. I del Título Preliminar del Código de los Niños y Adolescentes, peruano, declara que son niños desde la concepción hasta los doce años. 
El topo o tupu era una unidad económica. Toda la población participaba en las ceremonias de iniciación, como en el corte de pelo de los niños que era la fiesta de Rutuchicuy.

Para las jóvenes se daba el Quicuchicuy que servía para aislarlas por un tiempo, después cambiaban de peinado y eran adultas.

Para los muchachos se daba el Huarachicu, que tenía pruebas de fuerza y virilidad, después tenían el matrimonio y la distribución de los topos y medio topos, a hombres y mujeres.

Nótese que en quechua no existen las palabras "hambre", ni "pobreza", todos satisfacían sus necesidades y cuando había sequía del Silo o Tambo sacaban los alimentos guardados para esas probables ocasiones. También tenían trabajos de prevención de los desastres, sus ingenieros sabiamente desviaban las lluvias y desbordes de ríos, mediante la andenería, en todos los valles.

La familia peruana pre hispánica era monogámica, salvo casos de la nobleza, siempre autorizados por el Inca.

Desde la época pre incaica había en nuestros territorios la costumbre del matrimonio a prueba o servinacuy. Esta costumbre subsistió durante el Incanato y también en la colonia o virreinato; en la actualidad, en las comunidades alto andinas tiene vigor y es una costumbre previa al matrimonio religioso, pues muchos pobladores andinos conservan los ritos y celebraciones llegados con los europeos y, tal vez, por falta de conocimiento pueden creer que en el país continúa la validez oficial del matrimonio canónico. Como son comunidades aisladas, las autoridades o delegados de los Municipios no llegan. Incluso el Jefe de RENIEC, ha informado a la opinión pública que por falta de recursos presupuestales, la entidad que garantiza la identidad de los peruanos no se puede instalar en todo el territorio, situación que coloca en desventaja a los más pobres, entre los pobres del Perú.

La situación de muchas comunidades alto andinas y de la selva está pendiente de estudio e investigación. Esperamos que los censores del INEI durante el proceso del Censo de Hogares, que se realizará el próximo mes de setiembre 2017, puedan dar luces suficientes para que los titulares de los pliegos presupuestales puedan efectivamente atender en dichos territorios, hasta ahora olvidados por la burocracia. 


\section{LOS OBJETIVOS DEL MILENIO}

Como sabemos, el derecho delimita y legitima procesos sociales, muchas veces excluye a grupos de la humanidad, si se verifica la extrema pobreza en la que viven todavía muchas comunidades en casi todos los países de la tierra. Afirmamos esto, porque hay estadísticas de excepción en naciones donde los niños tienen asistencia plena a la escuela o el caso de Cuba, donde, se afirma, no existe un solo tuberculoso. Hay expertos que opinan que en ese caso, el clima los protege.

Dada la realidad universal, llegando al año 2000, los expertos de las Naciones Unidas, idearon que se debía planificar el desarrollo humano, partiendo del nuevo milenio, que se avecinaba.

Estudiaron los objetivos del Milenio, ODM, y para iniciar su aceptación y puesta en marcha a favor del desarrollo, se convocó a los Presidentes y Jefes de Estado, incluso al delegado de la Santa Sede, que tiene voz pero no voto en la ONU. Nótese que las Encíclicas Papales son documentos de consulta de muchos dirigentes políticos, y que una de las principales Cartas, fue la de Pablo VI de 17 de marzo de 1967, sobre el Desarrollo de los Pueblos.

El magno acontecimiento reunió a 189 Estados partes en el mes de mayo de 2002, fecha en la que los Jefes de Estado se comprometieron a trabajar hasta 2015 para cumplir los siguientes objetivos en la humanidad entera:

1.-Reducir la extrema pobreza y el hambre.

2.-Asegurar la plena educación primaria.

3.-Promover la igualdad de los sexos y la promoción de la mujer.

4.-Reducir la mortalidad infantil, especialmente de menores de 5 años de edad.

5.-Mejorar la salud materna y reducir la muerte materna.

6.-Combatir el VIH Sida, el paludismo y otras enfermedades.

7.-Asegurar el ambiente sostenible.

Estos objetivos figuraban en muchas legislaciones nacionales, como las del Perú. Es verdad que desde 1990 el Perú cuenta con el Código del Medio 
Ambiente; sin embargo, debe tenerse presente que en el caso peruano, muy pronto se modificó dicho código, salvaguardando intereses de las empresas transnacionales, particularmente las extractivas de riquezas mineras.

En cuanto a los dos primeros objetivos, referidos a familias y niños, se comenzó a estudiar el gran problema de la erradicación del trabajo infantil en el Perú. Varios ministros del ramo daban conferencias de prensa sobre los avances o sobre las comisiones especializadas que se instalaban, pero una mirada a nuestras calles, en cualquier ciudad o provincia y en la misma capital, es suficiente para darnos un informe general sobre la materia.

Cada uno de los objetivos es muy importante, pero, según los informes que debieron presentar en 2015, muchos cumplieron con la formalidad, pero alejados de la realidad de sus pueblos de origen, justificando en la mayoría de casos, en la falta de presupuesto.

\section{LA AGENDA 2030}

Del 25 al 27 de setiembre de 2015 se reunió en New York la Asamblea General de la Organización de Naciones Unidas, ONU, que adoptó la AGENDA 2030 para el Desarrollo Sostenible.

Todos los Estados partes de la ONU coincidieron en la necesidad de contar con un financiamiento integral para el desarrollo.

Adoptaron una nueva agenda de compromisos para 2030.

Los nuevos objetivos incidieron en la necesidad de trabajar por el desarrollo sostenible; los ODS, con 169 metas que buscan erradicar la pobreza, combatiendo las desigualdades y promoviendo la prosperidad, bajo el gran propósito de proteger el ambiente.

El documento se titula: "Transformando nuestro mundo" y busca el desarrollo, posterior a 2015.

Uno de los principales temas es el de la igualdad entre hombres y mujeres, dando la debida importancia al desarrollo de los derechos de la mujer y su empoderamiento en el centro de la agenda mundial, con la presencia de la organización ONU Mujeres.

La nueva agenda 2030 se funda en los Objetivos del Milenio, elaborados en el inicio del tercer milenio con propósitos señalados como urgentes, pero que subsisten en la fecha. 
Ha sido muy difícil reducir el hambre y la pobreza, así como las enfermedades y las desigualdades de trato a las personas sin oportunidades de acceder a suficientes puestos de trabajo, por ejemplo. Asimismo, se ha estudiado las dificultades de pueblos sin acceso al agua y al saneamiento necesario, en una agenda de sostenibilidad más amplia, si se compara con los objetivos $2000-2015$.

Los objetivos de la AGENDA van más lejos que los planteados anteriormente, pues abordan a fondo las causas de la pobreza y la desigualdad entre hombres y mujeres, así como la necesidad universal de desarrollo que beneficie a todas las personas, sin excepción; es decir, sin discriminar a nadie.

La nueva agenda consiste en un PLAN DE ACCIÓN para las personas y para el planeta, buscando la prosperidad, en un trabajo conjunto que enseñe a todas las generaciones y a gobernantes y gobernados que el desarrollo es el nuevo nombre de la paz.

De ahí que la agenda 2030 impulsará sociedades pacíficas, justas e inclusivas y exigirá la participación de todos los países, de las partes interesadas $\mathrm{y}$ de todos los individuos.

La agenda 2030 es muy ambiciosa en cuanto se propone acabar con la pobreza.

Así, entendemos que la agenda en marcha procura la prosperidad económica como partida, el desarrollo social y la protección ambiental para todos los países, especialmente el ODS $5^{7}$ referido a la igualdad entre hombres y mujeres.

Dada la dimensión de la Agenda 2030, la Comisión de Estadísticas de la ONU, en su 47 período de sesiones, en marzo 2016, se comprometió a trabajar por los objetivos de la Agenda. Y parece que sus actividades han comenzado, si consideramos que en el Perú el Instituto Nacional de Estadística e Informática, INEI se encuentra realizando el Censo de los Hogares, en forma minuciosa, interrogando a los miembros de cada familia, que perciben ingresos económicos.

Además, debe tenerse presente que en el esfuerzo de la AGENDA 2030 la ONU Mujeres se constituye en entidad observadora sobre los indicadores de los Objetivos de Desarrollo Social.

Objetivos de Desarrollo Sostenible (ODS) elaborados por la ONU. El Objetivo 5: Lograr la igualdad entre los géneros y empoderar a todas las mujeres y las niñas. 


\section{PROPUESTAS}

$1^{\circ}$. Para tener mayor éxito en este propósito de las Naciones Unidas, los Ministerios de Educación y del Trabajo deberían difundir los Objetivos de Desarrollo Sostenible, mediante cartillas, videos y películas, para que la niñez, la juventud y los trabajadores adultos, conozcan dichos objetivos y puedan participar activamente en el cumplimiento de sus fines.

$2^{\circ}$ Considerando que en la fecha la población peruana habla 47 idiomas nativos, las cartillas y documentación sobre la Agenda 2030, deberían ser traducidas a dichos idiomas, para asegurar la participación plena de las comunidades nativas, las que deberán ser instruidas sobre sus derechos culturales, económicos y sociales, como el caso de ser consultados antes de aprobarse las concesiones o exploraciones mineras en su territorio.

\section{CONCLUSIONES}

$1^{\circ}$. La ciudadanía consciente de su responsabilidad debe apoyar, desde las Universidades, Colegios Profesionales o Municipios los objetivos de la Agenda 2030, organizando comités cooperadores para la difusión cultural y social.

$2^{\circ}$. Las Universidades, los Colegios Profesionales, los Municipios y las Parroquias podrían organizar Comités Cooperadores con la ONU, en mérito del cumplimiento de la Agenda 2030; es decir, para proponer medidas que comprometan al presupuesto nacional o a la participación de las empresas en campañas como "Hambre Cero" o pleno empleo, tan necesarias en los barrios populares.

\section{REFERENCIAS}

Alzamora Valdez, Mario (1989). Derechos Humanos. Lima, Perú: Editorial Cultural Cuzco.

Ministerio de Justicia y Derechos Humanos (2015). Código Civil Peruano de 1984. Lima: Edición Oficial.

Congreso de la República ( 2016). Constitución Peruana de 1993. Lima, Perú: Edición Oficial.

Cornejo Chávez, Héctor (1994). Derecho Familiar Peruano. Dos tomos, Lima, Perú: Libreria "Studium".

Escalante, Ana Cecilia (2001). La contribución del Movimiento de Mujeres contemporáneo a la construcción de la democracia costarricense. La Democracia 
de Costa Rica ante el Siglo XXI. Jorge Rovira, editor. San José: Editorial de la Universidad de Costa Rica.

Geng Delgado, Federico (2005). Historia del Derecho Peruano, Segunda Edición. Lima, Perú : Ediciones Jurídicas.

Meza, Carmen y Hampe, Teodoro, compiladores y coautores (2007). La Mujer en la Historia del Perú. Lima, Perú: Ediciones Congreso de la República.

Meza Ingar, Carmen (1988). Discriminación mediante el Derecho. Lima, Perú: CONCYTEC.

Meza Ingar, Carmen (2001). El derecho a la información. Lima, Perú.

Meza Ingar, Carmen (1990). Ideas para un Código de Familia. Lima, Perú: CONCYTEC.

Meza Ingar, Carmen (1986). Más allá de la Igualdad. Lima, Perú: Amaru Editores.

Navarro, Cristina, Chinchilla Nuria y La Hera, Mireia (2012). Impacto de las políticas y prácticas de conciliación familia - trabajo en organizaciones venezolanas. Revista sobre Relaciones Industriales y Laborales. Caracas: Universidad Católica Andrés Bello.

Organización de Estados Americanos - OEA (1994). Convención de Belem do Pará para prevenir, sancionar y erradicar la Violencia contra la Mujer, Edición de 2002.

Organización de las Naciones Unidas - ONU (2014). Carta Universal de los Derechos Humanos.

Organización de las Naciones Unidas - ONU (1989). Convención de los Derechos del Niño.

Organización de las Naciones Unidas - ONU (1979). Convención para eliminar todas las formas de Discriminación de la Mujer.

Pablo VI (1967). Del Desarrollo de los Pueblos, Carta Encíclica. Ciudad de Vaticano.

Su Santidad León XIII (1891). Encíclica Rerum Novarum, Vaticano, edición en español, 1995.

Fecha de recepción: 31 de agosto de 2017

Fecha de aceptación: 15 de setiembre de 2017 